\title{
PhhC is an essential aminotransferase for aromatic amino acid catabolism in Pseudomonas aeruginosa
}

\author{
Wei Gu, † Jian Song, Carol A. Bonner, Gang Xie and Roy A. Jensen
}

Author for correspondence: Roy A. Jensen. Tel: +1 3523929677 . Fax: +1 3523925922.

e-mail : rjensen $(a)$ micro.ifas.ufl.edu

Department of Microbiology and Cell Science, University of Florida, Gainesville, FL 32611-0700, USA

\begin{abstract}
The phhC gene of Pseudomonas aeruginosa encodes a protein which is a member of the Family I aminotransferases. At high expression levels in the heterologous Escherichia coli system, PhhC can compensate for the absence of AspC (which functions in L-aspartate biosynthesis) and TyrB (which functions in aromatic biosynthesis). In the native organism, PhhC is essential for catabolism of either L-tyrosine or L-phenylalanine, as demonstrated by gene inactivation. This catabolic function of PhhC is consistent with its inclusion as the distal gene in the inducible phenylalanine hydroxylase operon. The presence of PhhC for catabolism of aromatic amino acids is required in spite of an existing multiplicity of other P. aeruginosa aminotransferases having a similar pattern of broad substrate specificity in vitro. This implies a spatial orientation of PhhC that effectively specializes it for aromatic amino acid catabolism.
\end{abstract}

Keywords: aromatic aminotransferase, phenylalanine catabolism, $p h h C$, phenylalanine hydroxylase operon, tyrosine catabolism

\section{INTRODUCTION}

PhhC from Pseudomonas aeruginosa is an aminotransferase belonging to the $\alpha$ subfamily of Family I aminotransferases (Jensen \& Gu, 1996). These aminotransferases participate in aspartate and/or aromatic amino acid biosynthesis. Individual subfamily members may be relatively specific for aromatic amino acids or for aspartate in some cases, but exhibit broad specificity and accommodate both substrate classes in other cases. $P$. aeruginosa $p h h C$ is the distal gene in a three-gene operon (Zhao et al., 1994) which includes $p h b A$ and phbB. PhhA is a pterin-dependent phenylalanine hydroxylase and $\mathrm{PhhB}$ is a carbinolamine dehydratase that functions in pterin recycling. The stop and start codons of $p h b B$ and $p h b C$ overlap and are thus probably translationally coupled. The operon is subject to positive regulation by a divergently transcribed regulatory protein which belongs to the large family of $\sigma^{54}$-dependent enhancer-binding proteins (Song \& Jensen, 1996).

The organizational inclusion of $p h b C$ within the $p h b$ operon implies an in vivo function as an aromatic

†Present address: Department of Biology, Rice University, Houston, TX 77005, USA.

Abbreviation: EPPS, $N$-(2-hydroxyethyl)piperazine- $N^{\prime}$-(3-propanesulfonic acid). aminotransferase. Operation of the phb operon in a catabolic mode would utilize the following initial steps: L-phenylalanine $\rightarrow$ L-tyrosine $\rightarrow$ 4-hydroxyphenylpyruvate. The latter supposition suggests that PhhC might be essential for L-phenylalanine and/or L-tyrosine catabolism. In view of the demonstrated expression of up to four additional aromatic aminotransferases in $P$. aeruginosa (Whitaker et al., 1982), the extent to which PhhC might be obligatory for a specialized role in catabolism was examined in this study.

\section{METHODS}

Bacterial strains, plasmids and media. All bacterial strains and plasmids used in this study are listed in Table 1. Luria-Bertani (LB) medium was used as enriched medium (Silhavy et al., 1984). The minimal medium used was the M9 formulation, except for Escherichia coli DL39, which was grown in the medium described by LeMaster \& Richards (1987). Where indicated, media were supplemented with ampicillin at $100 \mu \mathrm{g} \mathrm{ml}^{-1}$, kanamycin at $35 \mu \mathrm{g} \mathrm{ml}^{-1}$, thiamin at $17 \mu \mathrm{g} \mathrm{ml}^{-1}$ and $\mathrm{HgCl}_{2}$ at $15 \mu \mathrm{g} \mathrm{ml}^{-1}$. For solid media, $2 \%(\mathrm{w} / \mathrm{v})$ agar was added.

Crude-extract preparation and enzyme assays. Cultures of $E$. coli or $P$. aeruginosa were grown at $37^{\circ} \mathrm{C}$ with vigorous shaking in LB or minimal medium supplemented with appropriate antibiotics. The cells were harvested in the lateexponential phase of growth by centrifugation and resus- 
Table 1. Bacterial strains and plasmids

\begin{tabular}{|c|c|c|}
\hline $\begin{array}{l}\text { Strain or } \\
\text { plasmid }\end{array}$ & Relevant characteristics & Source or reference \\
\hline \multicolumn{3}{|l|}{ E. coli } \\
\hline S17-1 & $\begin{array}{l}[\mathrm{RP} 4-2(\mathrm{Tc}:: \mathrm{Mu})(\mathrm{Km}:: \mathrm{Tn} 7) \mathrm{Tra} \mathrm{IncP})] \\
\text { pro hsdR recA thi-1 } \mathrm{Tp}^{\mathrm{r}} \mathrm{Sm}^{\mathrm{r}}\end{array}$ & Simon et al. (1983) \\
\hline DL39 & $\lambda^{-}$aspC13 fnr-25 ilvE12 tyrB507 & LeMaster \& Richards (1987) \\
\hline \multicolumn{3}{|c|}{ P. aeruginosa } \\
\hline PAO-1 & Prototroph & Holloway (1955) \\
\hline RW8-24 & Phenylalanine auxotroph & Whitaker et al. (1982) \\
\hline JS104 & $\mathrm{Hg}^{\mathrm{r}} p h b C$ knockout & This study \\
\hline \multicolumn{3}{|l|}{ Plasmids } \\
\hline pUC18 & Ap ${ }^{r}$ lac'IPOZ' & Yanisch-Perron et al. (1985) \\
\hline pUC19 & $A p^{r} l_{a c}$ IPOZ' & Yanisch-Perron et al. (1985) \\
\hline pUFR004 & ColE1 $\mathrm{Cm}^{\mathrm{r}} \mathrm{Mob}^{+} \operatorname{mob}(P)$ & DeFeyter et al. (1990) \\
\hline pJS3A & $\begin{array}{l}3.7 \mathrm{~kb} \mathrm{BamHI}-\text { HindIII fragment of } p h b B-p h h \mathrm{C} \text { subcloned into the } \\
\text { BamHI/HindIII sites of pUC18 }\end{array}$ & This study \\
\hline pJS3B & $\begin{array}{l}3.7 \mathrm{~kb} \mathrm{BamHI}-H i n d I I I \text { fragment of } p h h B-p h h \mathrm{C} \text { subcloned into the } \\
\text { Bam HI/HindIII sites of pUC19 }\end{array}$ & This study \\
\hline pDG106 & $\mathrm{Hg}^{\mathrm{r}} \mathrm{Km}^{\mathrm{r}} \mathrm{P} 15 \mathrm{~A}$ replicon & Gambill \& Summers (1985) \\
\hline pJS101 & PstI-SmaI fragment of pDG106 inserted into pUC18 & Song \& Jensen (1996) \\
\hline
\end{tabular}

pended in $50 \mathrm{mM}$ potassium phosphate buffer ( $\mathrm{pH} 7 \cdot 0$ ), containing $1 \mathrm{mM}$ DTT. The cells were broken by sonication using an Ultratip Labsonic System (Lab-Line Instruments). The suspension was centrifuged at $150000 \mathrm{~g}$ for $65 \mathrm{~min}$ at $4{ }^{\circ} \mathrm{C}$. The supernatant fraction was collected and passed through a DG-10 Sephadex column $(1.5 \times 5.5 \mathrm{~cm})$, eluting with the same buffer. The resulting desalted preparation was the crude extract.

The ability of PhhC to function as an aspartate aminotransferase was assayed by two methods. (i) A continuous spectrophotometric assay was used to monitor oxaloacetate formation at $260 \mathrm{~nm}$ (Bonner \& Jensen, 1987). Reaction mixtures contained $2 \mathrm{mM}$ L-aspartate, $10 \mathrm{mM}$ 2-oxoglutarate in $50 \mathrm{mM}$ EPPS [N-(2-hydroxyethyl)piperazine- $N^{\prime}$-(3-propanesulfonic acid)] buffer at $\mathrm{pH} 8 \cdot 6$. (ii) A stopped HPLC assay was also used. Reaction samples were derivatized with $o$-phthalaldehyde in $18 \%$ methanol $/ 82 \% 20 \mathrm{mM}$ potassium phosphate at $\mathrm{pH} \mathrm{7.0} \mathrm{and} \mathrm{analysed} \mathrm{by} \mathrm{HPLC,} \mathrm{using} \mathrm{a} \mathrm{C}_{18}$ ODS reverse-phase column (Alltech). Under these conditions, Laspartate and L-glutamate exhibited retention times of 12.04 and $17 \cdot 26 \mathrm{~min}$, respectively. Aromatic aminotransferase was assayed as described by Gu et al. (1995). L-Phenylalanine and 2-oxoglutarate were used as the substrate combination, unless indicated otherwise. The Bradford assay (Bradford, 1976) was used for determination of protein concentrations.

Purification of cloned PhhC from E. coli DL39. E. coli DL39 carrying pJS3A was grown at $37^{\circ} \mathrm{C}$ in $41 \mathrm{LB}$ medium supplemented with ampicillin in a gyratory shaker until lateexponential phase. The cells were harvested by centrifugation, and the pellet was resuspended in $50 \mathrm{mM}$ potassium phosphate buffer ( $\mathrm{pH} 7 \cdot 0$ ) containing $1 \mathrm{mM}$ DTT. The cells were disrupted by sonication and centrifuged at $150000 \mathrm{~g}$ for $65 \mathrm{~min}$ at $4^{\circ} \mathrm{C}$. The crude extract was dialysed overnight against $2 \mathrm{l}$ of the above buffer with one change of buffer. A $1184 \mathrm{mg}$ a mount of protein was applied to a $3 \times 50 \mathrm{~cm} \mathrm{DE-52} \mathrm{column} \mathrm{equili-}$ brated with the buffer. The column was washed with $800 \mathrm{ml}$ buffer, and bound protein was eluted with $800 \mathrm{ml}$ of a linear salt gradient $(0-0.4 \mathrm{M} \mathrm{KCl})$ prepared in the same buffer. Fractions $(6 \mathrm{ml})$ were collected and assayed for aromatic aminotransferase activity. Fractions showing high enzyme activity were pooled and concentrated by means of an Amicon YM-10 membrane. The concentrated preparation was dialysed overnight against $5 \mathrm{mM}$ potassium phosphate buffer ( $\mathrm{pH} 7 \cdot 0$ ) containing $1 \mathrm{mM}$ DTT. A $288 \mathrm{mg}$ aliquot of protein was then loaded onto the bed of a $3 \times 16 \mathrm{~cm}$ Bio-Gel HTP column previously equilibrated with the above buffer. The column was washed with $500 \mathrm{ml}$ starting buffer and then eluted by application of a potassium phosphate gradient $(5-350 \mathrm{mM})$ in the same starting buffer. Fractions $(3.5 \mathrm{ml})$ were collected and aromatic aminotransferase activity was assayed. Fractions showing high enzyme activity in the wash eluate were pooled and concentrated by means of an Amicon YM-10 membrane. The concentrated preparation was dialysed overnight against $50 \mathrm{mM}$ potassium phosphate buffer (pH 7.0) containing $1 \mathrm{mM}$ DTT and $0.15 \mathrm{M} \mathrm{NaCl}$. Gel filtration was carried out by use of an FPLC-connected Superdex 75 column (Pharmacia) which had been previously equilibrated with the above buffer. Eluate fractions $(0.5 \mathrm{ml})$ were collected; those showing high aromatic aminotransferase activity were pooled and concentrated by an Ultrafree-15 centrifugal filter device (Millipore).

N-terminal amino acid sequencing of cloned PhhC. The purified enzyme preparation was denatured by SDS and resolved by SDS-PAGE. The protein was transferred to a PVDF membrane (Bio-Rad) by use of a protein miniblotting apparatus. After staining with Coomassie brilliant blue R-250, the band corresponding to $\mathrm{PhhC}$ was excised and sequenced by using an Applied Biosystems model 407A protein sequencer with an on-line $120 \mathrm{~A}$ phenylthiohydantoin analyser at the Protein Core Facility at the University of Florida.

Molecular mass determination. SDS-PAGE was carried out to determine the subunit molecular mass of the enzyme. Lysozyme $(14.4 \mathrm{kDa})$, soybean trypsin inhibitor $(21.5 \mathrm{kDa})$, carbonic anhydrase $(31 \mathrm{kDa})$, ovalbumin $(66 \mathrm{kDa})$ and phos- 
phorylase $b(97 \cdot 4 \mathrm{kDa})$ were used as molecular mass standards. Subunit size was also determined by matrix-assisted laser desorption/ionization time-of-flight mass spectrometry. A Vestec LaserTech Research linear instrument (Perceptive Biosystems) employing a nitrogen laser (337 nm), a $1.2 \mathrm{~m}$ flight tube, and an accelerating voltage of $10 \mathrm{kV}$ was used. The mass axis was set by calibration with insulin. Samples were diluted into $0.1 \%$ trifluoroacetic acid and mixed on the target with an equal volume of matrix consisting of a saturated solution of sinapinic acid dissolved in $40 \%$ acetonitrile and $0.1 \%$ trifluoroacetic acid. The mean was taken from 153 spectra and assigned using the GRAMS-LaserTech program.

The molecular mass of the native enzyme was estimated by FPLC using a Superdex 75 HR 10/30 column equilibrated with $50 \mathrm{mM}$ potassium phosphate buffer at $\mathrm{pH} 7 \cdot 4$ containing $0.15 \mathrm{M} \mathrm{NaCl}, 20 \%(\mathrm{v} / \mathrm{v})$ glycerol and $0.1 \mathrm{mM}$ pyridoxal phosphate. The enzyme $(250 \mu \mathrm{l}$ enzyme recovered from the DEAE-cellulose step) was eluted with the same buffer at a flow rate of $0.5 \mathrm{ml} \mathrm{min}^{-1}$. Standards used to calibrate the column were alcohol dehydrogenase $(150 \mathrm{kDa})$, bovine serum albumin $(66 \mathrm{kDa})$, carbonic anhydrase $(30 \mathrm{kDa})$ and cytochrome $\mathrm{C}$ $(12 \cdot 3 \mathrm{kDa})$.

Gene inactivation. The chromosomal $p h b C$ gene was insertionally inactivated by single-crossover recombination (Kamoun et al., 1992) as described by Song \& Jensen (1996). A truncated $p h b C$ fragment (' $p h b C$ ') was generated by PCR using the upper primer 5' GTCGAGCAGGAAACCACCAAGA $3^{\prime}$ and the lower primer 5' GTTGGCTACGCAGGTCGGTGAG 3'. Thus, 174 bp was eliminated from the $5^{\prime}$ end and $372 \mathrm{bp}$ from the $3^{\prime}$ end of the $1.2 \mathrm{~kb} p h b \mathrm{C}$ gene. The PCR-generated ' $p h b C$ ' fragment was first cloned into pUFR004 (a mobilizable suicide vector) to create pUFR/ ' $p h b C$ '. A Hg ${ }^{r}$ HindIII-cassette from pJS101 was then cloned into pUFR/' $p h b C$ ' to create pUFR/' $p h b C$ '/ $\mathrm{Hg}^{\mathrm{r}}$, which was used to transform $E$. coli S17-1 (a mobilizing strain). E. coli S17-1 harbouring pUFR/ $p h b C$ ' $/ \mathrm{Hg}^{\mathrm{r}}$ was used as a donor in biparental mating with $P$. aeruginosa, performed as described by Simon et al. (1983). The mating mixture was plated onto Pseudomonas isolation agar (Difco) plates containing $15 \mu \mathrm{g}$ $\mathrm{HgCl}_{2} \mathrm{ml}^{-1} . \mathrm{Hg}^{\mathrm{r}}$ colonies were isolated and the interruption of the chromosomal $p h b C$ gene by integration of the suicide vector was confirmed by Southern blot analysis (Sambrook et al., 1989) of $\mathrm{Hg}^{\mathrm{r}}$ isolates. The knockout mutant selected for further work was denoted strain JS104.

SDSPAGE and Western-blot analysis. SDS-PAGE was performed with a Mini-PROTEAN II cell (Bio-Rad) by the method of Laemmli (1970). Samples of exponential-phase cells were collected by centrifugation, and the pellets were suspended in gel-loading buffer and heated at $100^{\circ} \mathrm{C}$ for $10 \mathrm{~min}$. Samples of $5-10 \mu \mathrm{l}$ were loaded onto two SDS-12\% polyacrylamide gels. After electrophoretic separation, one gel was stained with Coomassie brilliant blue R-250, and the other gel was used for Western blotting. For comparison of different crude extracts, equivalent amounts of protein were applied. Western blots were performed according to Towbin et al. (1979).

\section{RESULTS}

\section{Catalytic capabilities of PhhC in vivo}

The ability of $P$. aeruginosa $p h b C$ to function in a biosynthetic direction under conditions of high expression in a heterologous system was tested. E. coli DL39 is a triple mutant, deficient in aspC, tyrB and ilvE,
Table 2. Ability of phhC to complement deficiencies of aspC, tyrB or ilvE in E. coli DL39/pJS3A

Agar plates contained minimal medium plus ampicillin. + indicates the presence of $50 \mu \mathrm{g} \mathrm{ml}^{-1}$ of the amino acid shown at the top of the column.

\begin{tabular}{|lccccc|}
\hline \multirow{2}{*}{ Test disc } & \multicolumn{3}{c}{ Supplementation } & Growth \\
\cline { 2 - 4 } & Tyr + Phe & Asp & Ile + Leu + Val & \\
\hline A & + & + & + & + \\
B & - & + & + & + \\
C & + & - & + & + \\
D & + & + & - & - \\
\hline
\end{tabular}

and thus requiring $\mathrm{L}$-aspartate, L-tyrosine, L-phenylalanine, L-leucine, L-isoleucine and L-valine for growth (LeMaster \& Richards, 1987). E. coli DL39 was transformed with pJS3A (a construct which carries $p h b B$ and phbC on a $P$. aeruginosa DNA insert), and ampicillinresistant colonies were selected on LB plates. Purified transformants were spread on minimal plates to provide confluent lawns. Sterile discs containing various combinations of the above-cited amino acids were placed on the lawns to evaluate the nutritional requirements of $E$. coli DL39 expressing phbC (Table 2). Growth occurred in the absence of L-tyrosine and L-phenylalanine or in the absence of $L$-aspartate, thus indicating the ability of $p h b C$ to compensate for the deficient $E$. coli tyrB and asp $C$ genes. On the other hand, L-isoleucine, L-leucine and $\mathrm{L}$-valine were required for growth, indicating that $p h b C$ could not complement the ilvE deficiency.

\section{Purification of $P$. aeruginosa PhhC from E. coli}

Crude extracts prepared from E. coli DL39/pJS3A possessed high aromatic aminotransferase activity, whereas comparable extracts from strain DL39 exhibited no detectable activity. When the $P$. aeruginosa DNA insert was placed in the opposite orientation $(E$. coli DL39/pJS3B), no aromatic aminotransferase activity was found. Thus, the $p h b C$ fragment either lacks a native promoter or has a promoter not recognized by E. coli, therefore requiring the orientation which allows use of the lac promoter in the vector.

PhhC was purified from E. coli DL39/pJS3A by use of three chromatography steps (Table 3 ). The hydroxylapatite chromatography step resolved two peaks of activity (Fig. 1a). An unbound species eluted in the wash fraction, and a second species eluted in the gradient. The leading peak of aminotransferase was of greater purity (Table 3, Fig. 2), and this fraction was applied to Superdex 75 in the final step of purification. The aminotransferase recovered was visualized as a single protein band following SDS-PAGE (Fig. 2). Mass spectrometry of the sample revealed a minor $16.3 \mathrm{kDa}$ protein contaminant. The molecular mass of the major band was estimated to be $43 \mathrm{kDa}$, in agreement with 
Table 3. Purification of the cloned P. aeruginosa PhhC from E. coli DL39/pJS3A

\begin{tabular}{|lcccc|}
\hline Purification step & $\begin{array}{c}\text { Total protein } \\
(\mathbf{m g})\end{array}$ & $\begin{array}{c}\text { Specific } \\
\text { activity }\end{array}$ & $\begin{array}{c}\text { Purification } \\
\text { factor }\end{array}$ & $\begin{array}{c}\text { Yield } \\
(\%)\end{array}$ \\
\hline Crude extract & 1184 & $1 \cdot 7$ & 1.0 & 100 \\
DEAE-cellulose & 320 & $3 \cdot 5$ & $2 \cdot 0$ & 55.6 \\
Hydroxylapatite & & & & \\
$\quad$ Gradient & 40 & $11 \cdot 9$ & 7.0 & 23.6 \\
$\quad$ Wash & 5 & 24.5 & 14.4 & 6.1 \\
Superdex 75† & 1 & 32.1 & 18.9 & 1.6 \\
\hline
\end{tabular}

"Specific activity expressed as $\mu \mathrm{mol} \mathrm{min}^{-1} \mathrm{mg}^{-1}$.

†The protein recovered from the hydroxylapatite wash fraction was applied.

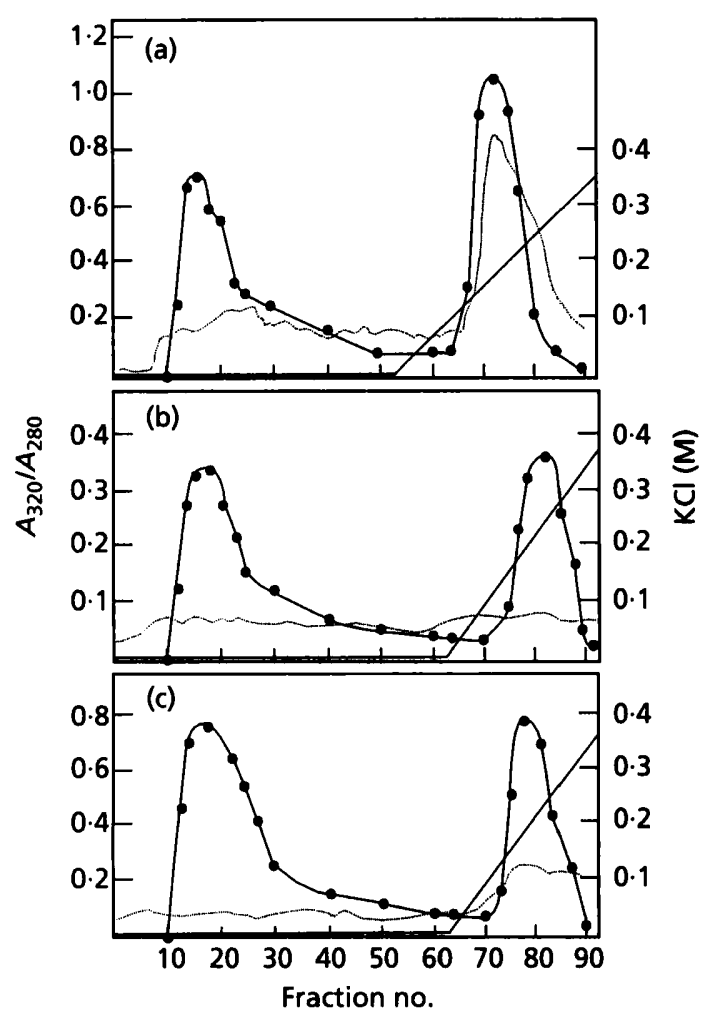

Fig. 1. PhhC hydroxylapatite elution profile. The protein applied was from: (a) the DEAE-cellulose step of purification; (b) the wash fraction shown in (a); (c) the gradient fraction shown in (a). All the gradient peaks eluted at about $0.1 \mathrm{M}$ potassium phosphate. Enzyme activity (O) was measured as formation of phenylpyruvate $\left(A_{320}\right)$ following the transamination of L-phenylalanine in the presence of 2oxoglutarate, as described in Methods. Dotted lines represent the protein profile $\left(A_{280}\right)$ of the eluate; the solid line represents the $\mathrm{KCl}$ concentration.

predictions based upon the DNA sequence. This was further confirmed by mass spectrometry (Fig. 3) which demonstrated a molecular mass of $43248 \mathrm{Da}$. Since a purification factor of only 19 -fold was required to obtain pure enzyme, it can be estimated that about $5 \%$ of the total protein in the original clone was PhC.

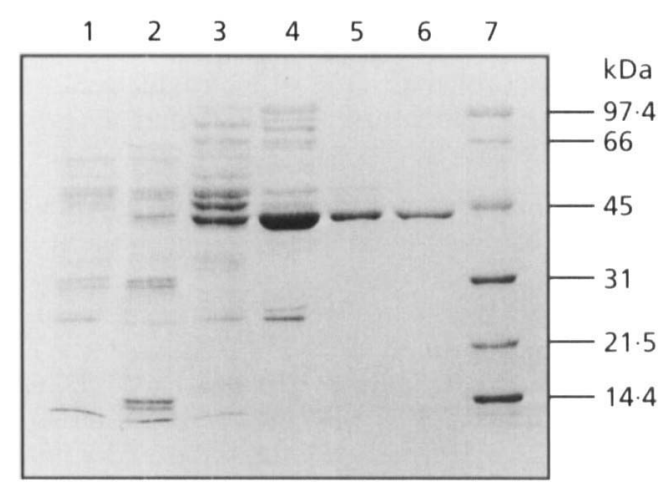

Fig. 2. SDS-PAGE of PhhC from E. coli DL39/pJS3A. The protein samples were run in a $12 \%$ gel and stained with Coomassie brilliant blue. Lanes: 1 , crude extract of DL39/pUC18; 2 , crude extract of DL39/pJS3A; 3, fraction collected after DE-52 chromatography; 4, gradient fraction collected after hydroxylapatite chromatography; 5, wash fraction collected after hydroxylapatite chromatography; 6, fraction collected after Superdex 75 chromatography; 7, molecular mass standards.

The two species of PhhC recovered after hydroxylapatite chromatography appear to be conformational isoforms at equilibrium. Appropriate experimental work was done to rule out trivial explanations such as an artifact of column packing, or that adsorption to the column might be a slow process which was not complete prior to elution. Both species eluted identically when individually subjected to gel filtration, indicating no detectable difference in molecular mass. $\mathrm{N}$-terminal amino acid sequencing of samples of either species showed identical $\mathrm{N}$ termini: SHFAKVARVP. This corresponds exactly with the deduced $\mathrm{N}$ terminus (Zhao et al., 1994), except that the starting $\mathrm{L}-\mathrm{methionine}$ had been processed. When either of the two species recovered from hydroxylapatite chromatography was reloaded onto the same column and eluted under the same conditions as before, the original bi-peaked profile was again obtained (Fig. 1b, c). The leading peak was characteristically broad, possibly consistent with a tendency for a new equilibrium of conformational isoforms to form during chromatography. These results were reproducible when 


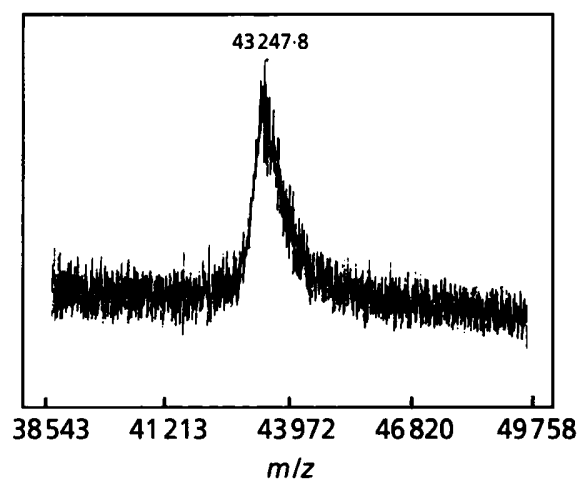

Fig. 3. Determination of the molecular mass of PhhC by matrixassisted laser desorption/ionization time-of-flight mass spectrometry. Mass spectrometry was carried out with a sample of purified PhhC from E. coli DL39/pJS3A as detailed in Methods.

the initial column was loaded with lesser amounts of protein, down to a level approaching the sensitivity of peak detection by enzyme assay.

Gel filtration experiments showed a native molecular mass of about $73 \mathrm{kDa}$. Since a native dimer of $86 \mathrm{kDa}$ is expected (see Discussion), PhhC may exhibit a physical shape that alters its migration in the gel. Gel filtration was carried out by FPLC in the presence of 2-oxoglutarate, L-phenylalanine and pyridoxal phosphate to see whether binding of active-site molecules would influence the elution position. A repetition of several experiments gave the same result: the apparent molecular mass was not influenced by the small molecules tested. In gel-filtration experiments, use of the same buffer which yielded two chromatographic forms from a hydroxylapatite matrix, yielded only a single peak at $73 \mathrm{kDa}$.

\section{Catalytic capabilities of PhhC in vitro}

The $\mathrm{pH}$ optimum for catalysis was determined over a $\mathrm{pH}$ range of $6 \cdot 0-10 \cdot 5$. Potassium phosphate buffer $(50 \mathrm{mM})$ was used for the range $\mathrm{pH} 6.0-7.5 ; 50 \mathrm{mM}$ EPPS buffer was used for the range of $\mathrm{pH} 8 \cdot 0-8 \cdot 8$; $50 \mathrm{mM}$ sodium borate buffer was used for the range $\mathrm{pH} 8 \cdot 8-10 \cdot 5$. Similar profiles were obtained when assays contained $10 \mathrm{mM}$ 2-oxoglutarate in combination with $2 \mathrm{mM}$ L-phenylalanine, L-tyrosine or L-aspartate. Optimal transamination rates occurred at $\mathrm{pH} 9 \cdot 0$, with $50 \%$ of the optimal rate occurring at $\mathrm{pH} 10.0$ and $\mathrm{pH} 7 \cdot 6$.

Substrate saturation curves were constructed in assays carried out in $50 \mathrm{mM}$ sodium borate buffer at $\mathrm{pH} 9.0$ and $22{ }^{\circ} \mathrm{C}$. L-Aspartate, L-phenylalanine and L-tyrosine were used as variable substrates in combination with 2oxoglutarate as the fixed substrate. 2-Oxoglutarate was also used as a variable substrate in combination with $\mathrm{L}-$ aspartate as the fixed substrate. $K_{\mathrm{m}}$ values were derived
PAO-1 JS104

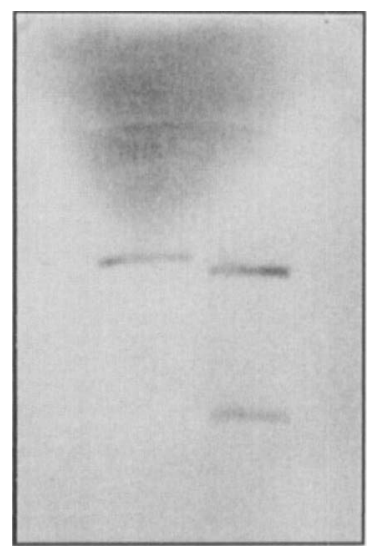

Fig. 4. Southern blot of chromosomal DNA from $P$. aeruginosa PAO-1 wild-type and phhC mutant JS104. Chromosomal DNA was completely digested with EcoRI and probed at high stringency with the truncated 'phhC' PCR fragment described in Methods.

from double-reciprocal plots for L-tyrosine $(1.2 \mathrm{mM}), 2$ oxoglutarate $(4.2 \mathrm{mM})$, L-aspartate $(5.0 \mathrm{mM})$ and Lphenylalanine $(14.3 \mathrm{mM})$. At saturating substrate concentrations in combination with $20 \mathrm{mM}$ 2-oxoglutarate, the ratio of specific activities obtained with L-tyrosine: $\mathrm{L}-$ phenylalanine: L-aspartate was $1 \cdot 0: 5 \cdot 7: 8 \cdot 3$.

\section{Insertional inactivation of phhC}

The $p h b C$ gene was interrupted as described in Methods to give mutant JS104 (Table 1). Gene interruption was verified by Southern-blot analysis of chromosomal DNA from wild-type PAO-1 and knockout-mutant JS104 (Fig. 4). Chromosomal DNA was completely digested with EcoRI and probed at high stringency with the ' $p h b C$ ' fragment (which lacks an EcoRI site). Two bands hybridized with ' $p h b C$ ' in mutant JS104, in contrast to the single band visualized with wild-type PAO-1. This is the expected result because of the presence of one EcoRI cleavage site in the vector.

Mutant JS104 was tested for its ability to use L-tyrosine or L-phenylalanine as the sole source of carbon. In contrast to the doubling times at $30^{\circ} \mathrm{C}$ observed for wild-type PAO-1 on L-tyrosine (doubling time $2.4 \mathrm{~h}$ ) or $\mathrm{L}$-phenylalanine (doubling time $25.5 \mathrm{~h}$ ), mutant JS104 was unable to utilize either amino acid as a carbon source. This cannot be attributed to downstream polarity effects of the insertion because the downstream gene $p b p G$ is unrelated to aromatic amino acid metabolism and has been characterized recently (Song et al., 1998). The gene downstream of $p b p G$ (yaeJ) is transcribed divergently. Inactivation of $p b p G$ had no effect upon aromatic amino acid catabolism (J. Song, unpublished). Mutant JS104 was able to utilize 4-hydroxyphenylpyruvate (doubling time $7 \mathrm{~h}$ ) or 4hydroxyphenylacetate (doubling time $1.8 \mathrm{~h}$ ) extremely 


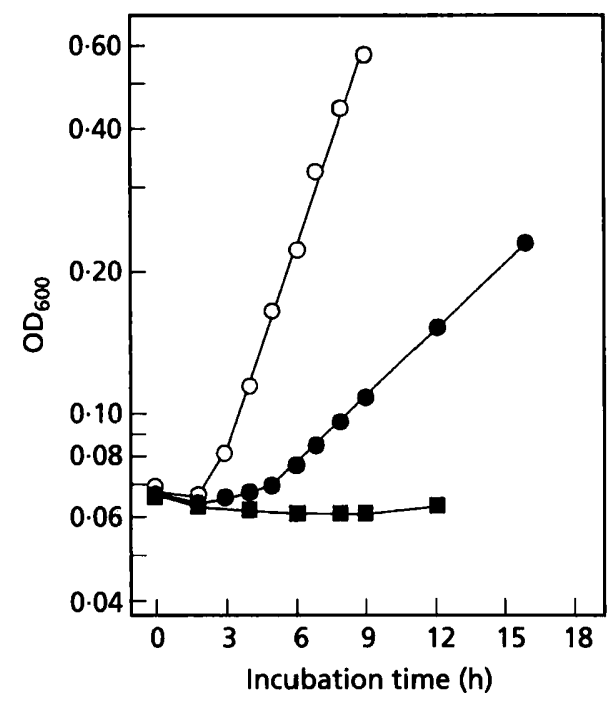

Fig. 5. Inability of phhC-inactivated mutant JS104 to utilize Ltyrosine as the sole source of carbon. A glucose-grown culture in the exponential phase was centrifuged and the pellet resuspended in minimal medium containing L-tyrosine (D), 4hydroxyphenylpyruvate (O), or 4-hydroxyphenylacetate (O). Turbidities of cultures at $30^{\circ} \mathrm{C}$ in sidearm flasks were monitored by measuring $O D_{600}$ at the indicated sampling times.

well as carbon sources, as shown in Fig. 5. Since growth is supported by 4-hydroxyphenylpyruvate but not by L-tyrosine, it would appear that little, if any, of the exogenously supplied L-tyrosine is converted to 4hydroxyphenylpyruvate by other aminotransferases that coexist with $\mathrm{PhhC}$ in $P$. aeruginosa.

\section{DISCUSSION}

\section{Apparent physical isoforms of PhhC}

Two different species of PhhC were eluted following hydroxylapatite column chromatography. The two separable species of $\mathrm{PhhC}$ obtained must have originated from a single gene since it was purified from an E. coli clone lacking an aromatic aminotransferase background. Each species exhibited an identical molecular mass $(43 \mathrm{kDa})$ and an identical $\mathrm{N}$-terminal amino acid sequence. When rechromatographed on the same column, each species was again resolved into a nearly equal mixture of the two isoforms. Taken together, these results ruled out the possibilities that interconvertible molecular-mass forms of the enzyme might be in equilibrium, that limited proteolysis might generate a second still-active form, or that some form of covalent modification, such as phosphorylation, might be in operation.

Since the clone used also expresses $p h b B$, to which $p h b C$ is translationally coupled (Zhao et al., 1994), we initially suspected the existence of a dissociable PhhB/PhhC complex. Although the complex should then possess a greater molecular mass, the small size $(13 \mathrm{kDa})$ of $\mathrm{PhhB}$ might have masked the difference. However, this was ruled out because the dissociated form of the enzyme (PhhC) should have no possibility to generate the PhhB/PhhC complex upon rechromatography. Furthermore, no PhhB was detected by Western analysis of either chromatographic peak using anti-PhhB polyclonal antibody.

We conclude that an equilibrium distribution of $\mathrm{PhhC}$ isoforms exists whose charge (or other) properties are discriminated by the hydroxylapatite matrix. Such protein conformers have been rigorously documented in the literature (Cao et al., 1998). P. aeruginosa PhhC may exemplify the 2-state class of dimer (Xu et al., 1998).

\section{Dimeric state of PhhC}

PhhC belongs to the Family I aminotransferase homology group (Jensen \& Gu, 1996). Well-studied members of this family share a mechanism of catalysis which requires homodimer formation. As is common for many dissociable enzyme oligomers (Traut, 1994), crucial catalytic sites are organized at subunit interfaces and are disrupted by subunit dissociation. Since $P$. aeruginosa $\mathrm{PhhC}$ is nested well within a homology group of four proteins for which crystal structures demonstrate an identical three-dimensional fold (Jeffery et al., 1998), the existence of a homodimer structure seems certain. Although a variety of size-exclusion chromatography experiments consistently yielded estimates of molecular mass $(73 \mathrm{kDa})$ somewhat smaller than expected $(86 \mathrm{kDa})$, the existence of the expected homodimer is indicated. Proteins having an asymmetrical shape often exhibit aberrant migration behaviour on a gel filtration matrix.

\section{Potential for biosynthetic function of PhhC in vivo}

In the native $P$. aeruginosa, $\mathrm{PhhC}$ appears to be uniquely oriented to aromatic amino acid catabolism. However, when highly expressed in E. coli, PhhC was also shown to suppress the deficiencies caused by mutant asp $C$ and tyrB genes. Thus, PhhC has the potential to function in both L-aspartate biosynthesis and aromatic amino acid biosynthesis, at least when expressed at high levels. Inactivation of $p h b C$ does not result in an inability to synthesize aromatic amino acids (or aspartate), consistent with the conclusion that it is not a biosynthetic enzyme.

Based upon a combination of $P$. aeruginosa mutant characterizations, and regulatory responses of multiple aminotransferase species to different growth conditions (Whitaker et al., 1982), two aminotransferase species (AT-2 and AT-4) were proposed to carry out aromatic biosynthesis under normal conditions. Under limiting conditions of growth imposed in the absence of AT-2, an aspartate aminotransferase was shown to support aromatic amino acid biosynthesis (similar to the ability of $E$. coli aspC to suppress a deficiency of $t y r B$ (Gelfand \& Steinberg, 1977). One might predict that a constitutive mutant of the $p h b$ operon (i.e. showing elevated expression levels of $p h b C$ ) would be able to suppress 
auxotrophic or bradytrophic phenotypes of mutants lacking aminotransferases normally engaged in aromatic biosynthesis in $P$. aeruginosa.

\section{Catabolic function of PhhC in vivo}

In contrast to the multiplicity of aminotransferase species which apparently can participate in aromatic biosynthesis, PhhC is absolutely required for utilization of either L-phenylalanine or L-tyrosine as the sole source of carbon. Expression of the structural genes in the $p h b$ operon is induced by well over an order of magnitude in the presence of aromatic amino acids (J. Song \& R. A. Jensen, unpublished). The previously described (Whitaker et al., 1982) aminotransferase AT-3 was the only species induced in the presence of aromatic amino acids (although only threefold), and could be synonymous with $\mathrm{PhhC}$.

In contrast to L-phenylalanine and L-tyrosine, catabolism of the closely related $\mathrm{L}$-arogenate has been shown not to depend upon expression of phbC (Fischer et al., 1997). Although L-arogenate can be catabolized through conversion to L-phenylalanine via periplasmic cyclohexadienyl dehydratase (in which case PhhC would be functional), an alternative and more robust pathway to 4-hydroxyphenylpyruvate apparently exists via its conversion to prephenate by oxidative deamination.

The $p h h$ operon is effectively induced by growth on Ltyrosine as a sole source of carbon (J. Song \& R. A. Jensen, unpublished). This meets physiological expectations in view of the essentiality of PhhC for tyrosine catabolism. The concomitant induction of PhhA and $\mathrm{PhhB}$, however, must be gratuitous under these conditions, since no apparent need for phenylalanine hydroxylase exists.

The absolute dependence of L-phenylalanine or Ltyrosine catabolism upon PhhC is striking in view of the multiplicity of aminotransferases present in $P$. aeruginosa that are capable of utilizing aromatic amino acids as substrates. This implies some sort of compartmentalization or physical sequestration, whereby $\mathrm{PhhC}$ specifically links with succeeding enzymes of catabolism. In this connection it is suggestive that 4-hydroxyphenylpyruvate dioxygenase, the enzyme using the product of PhhC-mediated catalysis, is an inner-membrane protein (G. Xie \& R. A. Jensen, unpublished). It is logical that initial enzymes of aromatic catabolism might be spatially associated with the cell exterior since many of them utilize molecular oxygen, and the cytoplasm is a highly reducing environment.

The genome sequencing project for $P$. aeruginosa (www.pseudomonas.com), which is near completion, will provide a basis for the systematic study at the molecular level of all of the aromatic aminotransferase enzymes. One can anticipate full elucidation of the primary roles of all of these aminotransferases and the extent to which they exhibit functional overlap under normal and forced environmental conditions.

\section{Substrate specificity of PhhC}

$\mathrm{PhhC}$ resembles its $E$. coli homologues in possessing broad substrate specificity, which potentially allows it to function as either an aromatic aminotransferase or an aspartate aminotransferase. PhhC has a significantly greater affinity for L-tyrosine than for either L-phenylalanine or L-aspartate in vitro. $\mathrm{L}-\mathrm{Ty}$ rosine is presumably the physiological substrate, even when L-phenylalanine is catabolized as the carbon source (i.e. PhhA first converts L-phenylalanine to L-tyrosine). At saturating substrate levels, however, both L-phenylalanine and L-aspartate yield greater specific activities than does L-tyrosine.

Among homologues of $\mathrm{PhhC}, \mathrm{AspC}$ and TyrB from E. coli have been studied to determine the variation of catalytic residues which influence whether L-aspartate or aromatic amino acids are favoured as substrates (Onuffer \& Kirsch, 1995). PhhC is clearly dedicated to function with aromatic substrates. In view of this, it is curious that the pattern of critical catalytic residues identified by Onuffer \& Kirsch (1995) as important for substrate discrimination resembles the pattern of AspC more than TyrB.

\section{ACKNOWLEDGEMENTS}

This publication is Florida Agriculture Experiment Station Journal Series no. R-05987.

\section{REFERENCES}

Bonner, C. A. \& Jensen, R. A. (1987). Prephenate aminotransferase. Methods Enzymol 142, 479-487.

Bradford, M. M. (1976). A rapid and sensitive method for the quantitation of microgram quantities of protein utilizing the principle of protein-dye binding. Anal Biochem 72, 248-254.

Cao, Y., Musah, R. A., Wilcox, S. K., Goodin, D. B. \& Duncan, E. M. (1998). Protein conformer selection by ligand binding observed with crystallography. Protein Sci 7, 71-78.

DeFeyter, R., Kado, C. I. \& Gabriel, D. W. (1990). Small, stable shuttle vectors for use in Xanthomonas. Gene 88, 65-72.

Fischer, R. S., Song, J., Gu, W. \& Jensen, R. A. (1997). L-Arogenate is a chemoattractant which can be utilized as the sole source of carbon and nitrogen by Pseudomonas aeruginosa. Appl Environ Microbiol 63, 567-573.

Gambill, D. B. \& Summers, A. O. (1985). Versatile mercuryresistant cloning and expression vectors. Gene 39, 293-297.

Gelfand, D. H. \& Steinberg, R. A. (1977). Escherichia coli mutants deficient in the aspartate and aromatic amino acid aminotransferases. J Bacteriol 130, 429-440.

Gu, W., Zhao, G., Eddy, C. \& Jensen, R. A. (1995). Imidazole acetol phosphate aminotransferase in Zymomonas mobilis: molecular genetic, biochemical and evolutionary analyses. J Bacteriol 177, 1576-1584.

Holloway, B. W. (1955). Genetic recombination in Pseudomonas aeruginosa. J Gen Microbiol 13, 572-581.

Jeffery, C. J., Barry, T., Doonan, S., Petsko, G. A. \& Ringe, D. (1998). Crystal structure of Saccharomyces cerevisiae cytosolic aspartate aminotransferase. Protein Sci 7, 1380-1387.

Jensen, R. A. \& Gu, W. (1996). Evolutionary recruitment of biochemically specialized subdivisions of Family I within the 
protein superfamily of aminotransferases. J Bacteriol 178, 2161-2171.

Kamoun, S., Kamdar, H. V., Tola, E. \& Kado, C. I. (1992). Incompatible interactions between crucifers and Xanthomonas campestris involve a vascular hypersensitive response: role of the hrpX locus. Mol Plant-Microbe Interact 5, 22-33.

Laemmli, U. K. (1970). Cleavage of structural proteins during the assembly of the head of bacteriophage T4. Nature 227, 680-685.

LeMaster, D. M. \& Richards, F. M. (1987). NMR sequential assignment of Escherichia coli thioredoxin utilizing random fractional deuteriation. Biochemistry 27, 142-150.

Onuffer, J. \& Kirsch, J. F. (1995). Redesign of the substrate specificity of Escherichia coli aspartate aminotransferase to that of Escherichia coli tyrosine aminotransferase by homology modeling and site-directed mutagenesis. Protein Sci 4, 1750-1757.

Sambrook, J., Fritsch, E. F. \& Maniatis, T. (1989). Molecular Cloning: a Laboratory Manual, 2nd edn. Cold Spring Harbor, NY: Cold Spring Harbor Laboratory.

Silhavy, T. J., Berman, M. I. \& Enquist, I. W. (1984). Experiments with Gene Fusions. Cold Spring Harbor, NY: Cold Spring Harbor Laboratory.

Simon, R., Priefer, U. \& Puhler, A. (1983). A broad-host-range mobilization system for in vitro genetic engineering: transposon mutagenesis in gram-negative bacteria. Bio/Technology 1, 784-791.

Song, J. \& Jensen, R. A. (1996). PhhR, a divergently transcribed activator of the phenylalanine hydroxylase gene cluster of Pseudomonas aeruginosa. Mol Microbiol 22, 497-507.
Song, J., Xie, G., Elf, P. K., Young, K. D. \& Jensen, R. A. (1998). Comparative analysis of Pseudomonas aeruginosa penicillinbinding protein 7 in the context of its membership in the family of low-molecular-mass PBPs. Microbiology 144, 975-983.

Towbin, H., Staehelin, T. \& Gordon, J. (1979). Electrophoretic transfer of proteins from polyacrylamide gels to nitrocellulose sheets : procedure and some applications. Proc Natl Acad Sci USA 76, 4350-4354.

Traut, T. W. (1994). Dissociation of enzyme oligomers: a mechanism for allosteric regulation. Crit Rev Biochem Mol Biol 29, 125-163.

Whitaker, R. J., Gaines, C. G. \& Jensen, R. A. (1982). A multispecific quintet of aromatic aminotransferases that overlap different biochemical pathways in Pseudomonas aeruginosa. J Biol Chem 257, 13550-13556.

Xu, D., Tsai, C.-J. \& Xu, D. (1998). Mechanism and evolution of protein dimerization. Protein Sci 7, 533-544.

Yanisch-Perron, C., Vierira, J. \& Messing, J. (1985). Improved M13 phage cloning vectors and host strains: nucleotide sequences of the M13mp18 and pUC19 vectors. Gene 33, 103-119.

Zhao, G., Xia, T., Song, J. \& Jensen, R. A. (1994). Pseudomonas aeruginosa possesses homologues of mammalian phenylalanine hydroxylase and $4 \alpha$-carbinolamine dehydratase/DCoH as part of a three-component gene cluster. Proc Natl Acad Sci USA 91, $1366-1370$.

Received 6 March 1998; revised 5 June 1998; accepted 13 July 1998. 